Arq. Bras. Med. Vet. Zootec., v.68, n.3, p.739-747, 2016

\title{
Estratégias para minimizar os efeitos de um ambiente térmico adverso para frangos de corte
}

[Strategies to minimize the adverse thermal environment in broiler chickens]

\author{
P.M. Oliveira, M.J.A. Faria Júnior, M.Garcia Neto
}

Faculdade de Medicina Veterinária - Unesp - Araçatuba, SP

\begin{abstract}
RESUMO
O calor limita a produção de frangos de corte. Este trabalho avaliou as interações entre o termocondicionamento precoce (TCP) e o uso do equilíbrio eletrolítico (EE) sobre o desempenho e as características da carcaça das aves. Assim, o balanço eletrolítico $(\mathrm{BE}=\mathrm{Na}+\mathrm{K}-\mathrm{Cl})$ foi ajustado em $350 \mathrm{mEq} / \mathrm{kg}$, e a relação eletrolítica $(\mathrm{K}+\mathrm{Cl}) / \mathrm{Na}$ em 3:1, pelo programa PPFR. O experimento foi realizado no setor de Zootecnia da Faculdade de Medicina Veterinária de Araçatuba/Unesp. Alojaram-se 240 pintos machos de um dia de idade, linhagem Cobb-500 ${ }^{\circledR}$, em bateria metálica com 24 divisões e aquecimento elétrico automático. O delineamento experimental foi inteiramente ao acaso, em arranjo fatorial $2 \times 2$, totalizando quatro tratamentos com seis repetições e 10 aves por parcela experimental. O TCP ocorreu no quinto dia de idade, por 24 horas, a $36,5^{\circ} \mathrm{C}$, em metade do lote. Posteriormente, as aves foram transferidas para um galpão climatizado e alojadas em boxes, da mesma forma que a outra parcela que não passou pelo TCP. Avaliaram-se os efeitos do estresse calórico crônico (seis horas a $32^{\circ} \mathrm{C}$ ) aplicado do $35^{\circ}$ ao $39^{\circ}$ dia de idade. Foram monitoradas a temperatura e a umidade do ar, bem como a temperatura de globo negro. Alimentação e água foram fornecidas ad libitum. Calcularam-se os dados de desempenho zootécnico e a taxa de mortalidade das aves. Submeteramse os resultados à análise de variância e à comparação de médias pelo teste de Tukey. Não houve interação entre o TCP e o EE sobre o desempenho e as características da carcaça das aves. As estratégias, TCP e EE, mostraram-se ineficazes para amenizar os efeitos do estresse calórico crônico em frangos de corte.
\end{abstract}

Palavras-chave: aves, eletrólitos, equilíbrio ácido-base, termocondicionamento precoce, transtornos de estresse por calor

\begin{abstract}
Heat limits the production of broilers. This study evaluated the interactions between early thermal conditioning (ETC) and the electrolyte balance (EB) on performance and characteristics of birds' carcass. Thus, the electrolyte balance $\left(\mathrm{BE}=\mathrm{Na}^{+}+\mathrm{K}^{+}-\mathrm{Cl}^{-}\right)$, was set to $350 \mathrm{mEq} / \mathrm{kg}$ and electrolyte ratio $\left(\mathrm{K}^{+}+\mathrm{Cl}^{-}\right) / \mathrm{Na}^{+}$in $3: 1$ by the PPFR program. The experiment was carried out at the Animal Science department of the Faculty of Veterinary Medicine of Araçatuba / UNESP. 2401 day old Cobb-500 ${ }^{\circledR}$ male chicks were used, lodged in metal batteries with 24 divisions and automatic electric heating. The experimental design was completely randomized in a 2x2 factorial arrangement, totaling 4 treatments with 6 replicates and 10 birds per experimental plot. ETC occurred on the 5th day of age for 24 hours at $36.5^{\circ} \mathrm{C}$ in half of the batch. Subsequently, these birds were transferred to an environmentally controlled shed and were grown in boxes, in the same way as the other half that had not received ETC treatment. The effects of chronic heat stress (6 hours at $32^{\circ} \mathrm{C}$ ) applied from the 35th through the 39th day of age were evaluated. Temperature and air humidity, as well black-globe temperature were monitored electronically. Food and water were provided ad libitum. The growth performance data and the mortality rate of birds were measured. The results were subjected to analysis of variance and comparison of means was done by Tukey test. There were no interaction effects between ETC and EB on performance and characteristics of birds' carcass. The ETC and EB strategies proved to be ineffective to mitigate the effects of chronic heat stress in broilers.
\end{abstract}

Keywords: acid-base equilibrium, birds, early thermal conditioning, electrolytes, heat stress disorders

Recebido em 19 de agosto de 2015

Aceito em 7 de janeiro de 2016

E-mail: patricia_oliveira77@hotmail.com 


\section{INTRODUÇÃO}

O Brasil é o terceiro maior produtor mundial de carne de frango, produzindo 12,3 milhões de toneladas (Ubabef, 2014). Embora apresente um mercado promissor, a avicultura brasileira possui como maior adversário as condições climáticas inadequadas, pois trata-se de um país de clima tropical, onde altas temperaturas e alta umidade relativa são desafios constantes ao desempenho zootécnico de frangos de corte.

Para Salgado e Nääs (2010), as perdas produtivas na produção de frangos de corte, em locais com climas onde prevalecem altas temperaturas diárias, são de grande magnitude, uma vez que abrangem perdas diretas e indiretas.

O termocondicionamento precoce é utilizado a fim de se obter maior tolerância ao calor. Já a manipulação do equilíbrio ácido-base das aves, por meio da adição de compostos como bicarbonato de sódio $\left(\mathrm{NaHCO}_{3}\right)$, cloreto de potássio $(\mathrm{KCl})$, cloreto de cálcio $\left(\mathrm{CaCl}_{2}\right)$ e cloreto de amônia $\left(\mathrm{NH}_{4} \mathrm{Cl}\right)$, via água e/ou ração, também atua para minimizar as perdas decorrentes do estresse por calor, visto que o equilíbrio ácido-base é alterado.

A formulação de rações baseada no conceito de balanço eletrolítico da dieta é caracterizada pela busca permanente do equilíbrio ácido-base, visando corrigir suas distorções decorrentes do estresse calórico. Desse modo, contribui na manutenção do equilíbrio ácido-base, pois minimiza a predisposição das aves à alcalose respiratória, em consequência do estresse calórico, evitando-se os reflexos negativos no ganho de peso, em decorrência da menor ingestão de alimento e da pior conversão alimentar (Teeter et al., 1985).

Mongin (1981) recomenda a necessidade de se adequar a dieta não apenas ao BE, pela diferença $\left[\mathrm{Na}^{+}\right]+\left[\mathrm{K}^{+}\right]-\left[\mathrm{Cl}^{-}\right]$, mas também à relação eletrolítica (RE) $\left(\left[\mathrm{K}^{+}+\mathrm{Cl}^{-}\right] / \mathrm{Na}^{+}\right)$.

Portanto, uma dieta formulada com valor adequado para o BE e ajustada, também, à relação dos eletrólitos fundamentais $\mathrm{K}^{+}, \mathrm{Cl}^{-}, \mathrm{Na}^{+}$ é imprescindível para se obter uma ração que atenda às necessidades nutricionais dos frangos de corte e, assim, garantir a manutenção da homeostase ácido-base, e evitar os transtornos metabólicos, especialmente, em condições de estresse calórico.

$\mathrm{O}$ presente experimento teve como finalidade avaliar as possíveis interações entre 0 termocondicionamento precoce, ao quinto dia de idade, e o equilíbrio eletrolítico da dieta, com base em modificações no balanço eletrolítico $\left(\mathrm{BE}=\mathrm{Na}^{+}+\mathrm{K}^{+}-\mathrm{Cl}^{-}\right)$e na relação eletrolítica $\left[\mathrm{RE}=\left(\mathrm{K}^{+}+\mathrm{Cl}^{-}\right) / \mathrm{Na}^{+}\right]$, sobre o desempenho e as características de carcaça dos frangos de corte.

\section{MATERIAL E MÉTODOS}

O experimento foi realizado no setor de Zootecnia da Faculdade de Medicina Veterinária de Araçatuba/Unesp. Foram utilizados 240 pintos machos de um dia de idade, da linhagem Cobb$500^{\circledR}$, no período de um a 42 dias de idade.

Os tratamentos foram constituídos por dietas, cujo balanço eletrolítico $\left(\mathrm{BE}=\mathrm{Na}^{+}+\mathrm{K}^{+}-\mathrm{Cl}^{-}\right)$foi ajustado em $350 \mathrm{mEq} / \mathrm{kg}$, e a relação eletrolítica $\left[\mathrm{RE}=\left(\mathrm{K}^{+}+\mathrm{Cl}^{-}\right) / \mathrm{Na}^{+}\right]$em 3:1, combinados com a técnica do termocondicionamento precoce, realizada no quinto dia de idade dos pintainhos, durante 24 horas, a $36,5^{\circ} \mathrm{C}$, somente na metade do lote. Posteriormente, do $35^{\circ}$ ao $39^{\circ}$ dia de idade, todas as aves foram expostas ao estresse calórico crônico, durante seis horas por dia, a $32^{\circ} \mathrm{C}$.

O delineamento experimental foi inteiramente ao acaso, em arranjo fatorial $2 \times 2$ (com e sem termocondicionamento precoce (TCP) e com e sem equilíbrio eletrolítico (EE)), totalizando quatro tratamentos, com seis repetições e 10 aves por parcela experimental, totalizando 240 aves.

Os pintainhos foram alojados, do primeiro ao quinto dia de idade, em baterias metálicas com 24 divisões. Cada divisão das baterias apresentava $0,95 \mathrm{~m}$ de largura por $0,52 \mathrm{~m}$ de comprimento, piso de arame, comedouros do tipo calha e bebedouros automáticos tipo copopressão. Posteriormente, foram transferidos para os boxes localizados em galpão de alvenaria climatizado, com sistema de resfriamento evaporativo adiabático e ventilação de pressão negativa. Em seu interior, as aves foram distribuídas em 24 boxes, onde permaneceram do sexto ao $42^{\circ}$ dia de idade. Cada um dos boxes possuía $1,4 \mathrm{~m}$ de largura por $3,0 \mathrm{~m}$ de comprimento, piso composto por cama de 
maravalha, comedouros tubulares e bebedouros automáticos pendulares, todos com altura regulável, acompanhando o crescimento das aves.

Utilizaram-se, inicialmente, como fonte de aquecimento automatizado, lâmpadas de $60 \mathrm{~W}$, dentro das baterias, e resistências cônicas de porcelana, uma em cada boxe, durante os 15 primeiros dias de criação.
As rações experimentais (Tab. 1) foram formuladas à base de milho, farelo de soja, óleo, suplemento vitamínico, suplemento mineral, calcário e fosfato bicálcico, seguindo-se as recomendações de Rostagno et al. (2011). Os sais $\left(\mathrm{NaCl}, \mathrm{NaHCO}_{3}, \mathrm{KCL}, \mathrm{KHCO}_{3}\right.$ e $\left.\mathrm{CaCl}_{2}\right)$ foram fixados de acordo com as necessidades mínimas em $\mathrm{Na}^{+}, \mathrm{K}^{+}$e $\mathrm{Cl}^{-}$, e o ajuste eletrolítico, necessário para cada ração experimental, foi calculado por meio do programa PPFR para frangos de corte.

Tabela 1. Composição percentual das rações fornecidas para os frangos de corte nas fases inicial, crescimento e terminação, calculada pela planilha eletrônica PPFR*, segundo as Tabelas Brasileiras (2011)

\begin{tabular}{|c|c|c|c|c|c|c|c|}
\hline \multirow{2}{*}{ Ingrediente } & & \multicolumn{3}{|c|}{ Com equilíbrio eletrolítico } & \multicolumn{3}{|c|}{ Sem equilíbrio eletrolítico } \\
\hline & & Inicial & Crescimento & Terminação & Inicial & Crescimento & Terminação \\
\hline Milho (7,88\%) & $\%$ & 49,159 & 54,480 & 57,835 & 51,022 & 56,771 & 60,382 \\
\hline Soja farelo $(45 \%)$ & $\%$ & 40,452 & 35,131 & 31,997 & 40,140 & 34,747 & 31,571 \\
\hline Óleo de soja & $\%$ & 5,268 & 5,754 & 5,822 & 4,630 & 4,969 & 4,950 \\
\hline Fosfato bicálcico & $\%$ & 1,677 & 1,289 & 1,083 & 1,675 & 1,286 & 1,080 \\
\hline Calcário calcítico & $\%$ & 1,036 & 0,864 & 0,772 & 1.038 & 0,866 & 0,775 \\
\hline $\begin{array}{l}\text { Polimax F - pré-inicial } \\
\text { (Fatec) }\end{array}$ & $\%$ & 0,657 & 0,597 & 0,469 & 0,657 & 0,597 & 0,469 \\
\hline $\begin{array}{l}\text { Sulfato de potássio } \\
\left(\mathrm{K}_{2} \mathrm{SO}_{4}\right)\end{array}$ & $\%$ & 0,618 & 0,795 & 0,896 & & & \\
\hline $\begin{array}{l}\text { Bicarbonato de sódio } \\
\left(\mathrm{NaHCO}_{3}\right)\end{array}$ & $\%$ & 0,614 & 0,635 & 0,656 & & & \\
\hline Sal comum & $\%$ & 0,201 & 0,173 & 0,149 & 0,516 & 0,476 & 0,448 \\
\hline L-Lisina & $\%$ & 0,151 & 0,150 & 0,162 & 0,157 & 0,157 & 0,170 \\
\hline DL-Metionina & $\%$ & 0,124 & 0,104 & 0,132 & 0,122 & 0,101 & 0,129 \\
\hline L-Treonina & $\%$ & 0,043 & 0,028 & 0,026 & 0,043 & 0,028 & 0,026 \\
\hline
\end{tabular}

*Programa Prático de Formulação de Rações (https://sites.google.com/site/ppfrparaexcel2007ousuperior/). $\mathrm{K}_{2} \mathrm{SO}_{4}$ : sulfato de potássio; $\mathrm{NaHCO}_{3}$ : bicarbonato de sódio.

Durante o TCP, os pintainhos receberam alimentação e água ad libitum, porém, no reservatório de água, foi adicionado gelo, a cada duas horas, para manter a temperatura da água adequada para consumo.

$\mathrm{Na}$ fase de terminação, todas as aves foram submetidas a um estresse calórico crônico conforme Gonzales - Esquerra e Leeson (2006).

Mensurou-se a temperatura superficial das aves, aferida na face medial da asa de três aves por parcela experimental, por meio de um termômetro infravermelho, durante o primeiro, o terceiro e o último dia do estresse calórico crônico.

Avaliaram-se o ganho de peso corporal, o consumo de ração, o índice de conversão alimentar, a taxa de sobrevivência após TCP e após estresse calórico crônico e a taxa de mortalidade.

O peso das aves e a quantidade de ração foram mensurados no primeiro, sétimo, $35^{\circ}$ e $42^{\circ}$ dias de criação, para posterior cálculo do ganho de peso, do consumo de ração e da conversão alimentar.

O ganho de peso, o consumo de ração e a conversão alimentar foram calculados nos períodos de um a sete dias, oito a 35 dias e 36 a 42 dias. A taxa de mortalidade foi avaliada nos períodos de um a sete, um a 35 e um a 42 dias, trabalhando-se, dessa forma, com os dados acumulados. Todas as aves mortas foram pesadas, identificadas por tratamento e por idade e, posteriormente, descartadas em composteira do próprio setor de Zootecnia da Faculdade de Medicina Veterinária de Araçatuba/Unesp. 
Utilizando-se três aves de cada unidade experimental, em um total de 72 aves, foram determinados os pesos da carcaça, da gordura cavitária, do coração e do fígado, e calculados o rendimento de carcaça, a relação percentual entre peso do coração e da carcaça e a relação percentual entre peso do fígado e da carcaça.

Foram determinadas as condições microclimáticas próximas às aves, em 12 parcelas experimentais, entre os tratamentos testados, por meio dos registros de temperatura e umidade relativa do ar e temperatura de globo negro. Os termômetros de globo negro foram confeccionados com sensores/registradores DS1922L-F5 (Dallas/Maxim), com faixa de operação entre $-40^{\circ}$ e $85^{\circ} \mathrm{C}$, acurácia de $0,5^{\circ} \mathrm{C}$ e capacidade de armazenamento de 8192 leituras, enquanto as medidas da temperatura e umidade relativa do ar foram realizadas com sensores/registradores Hygrochron DS1923-F5, com faixa de operação entre -20 e $85^{\circ} \mathrm{C}$, para temperatura, e de 0 a $100 \%$, para umidade relativa (UR), com acurácia, para leituras de temperatura, de $0,5^{\circ} \mathrm{C}$, e de UR, de $0,6 \%$; com capacidade de armazenamento idêntica ao sensor anteriormente descrito, foram instalados próximos às unidades experimentais.

Os resultados de desempenho e da avaliação de composição corporal foram submetidos à análise de variância, e as médias foram comparadas utilizando-se o teste de Tukey a $5 \%$ de probabilidade. Os dados de mortalidade foram transformados em $\sqrt{x+1}$. O projeto seguiu os Princípios Éticos da Experimentação Animal (Cobea) e foi aprovado pelo Comitê de Ética no Uso de Animais (Ceua), de acordo com o processo $\mathrm{N}^{\mathrm{o}} 00887-2012$.

\section{RESULTADOS E DISCUSSÃO}

As variáveis microclimáticas dos ambientes de crescimento das aves, obtidas por meio dos sensores instalados próximo às parcelas experimentais, revelaram que a temperatura média registrada pelos globos negros durante a permanência dos pintainhos nas baterias metálicas, do primeiro ao sexto dia de criação, foi de $31,4 \pm 0,7^{\circ} \mathrm{C}$, enquanto a média das temperaturas mínimas situou-se em $23,3 \pm 0,3^{\circ} \mathrm{C}$, e o valor médio das temperaturas máximas foi de $37,1 \pm 1,5^{\circ} \mathrm{C}$, obtido durante o termocondicionamento precoce, no quinto dia de vida dos pintainhos. Por sua vez, a temperatura média do ar, no mesmo período, foi de $31,3 \pm 0,8^{\circ} \mathrm{C}$; de $21,8 \pm 0,4^{\circ} \mathrm{C}$ foi a média das temperaturas mínimas; e de $36,5 \pm 1,5^{\circ} \mathrm{C}$ a média das temperaturas máximas. Os valores médios, entre os sensores, para as umidades relativas do ar média, mínima e máxima foram, respectivamente, de $58,7 \pm 1,5 \%, 48,0 \pm 2,8 \%$ e $83,8 \pm 1,7 \%$.

Pode-se comprovar que, diante dos valores apresentados referentes à temperatura média do ar, os pintainhos encontravam-se em condições de conforto térmico, visto que, de acordo com Abreu e Abreu (2011), a temperatura da zona de conforto térmico para a fase inicial é de $35^{\circ} \mathrm{C}$.

Para Menegali et al. (2013), valor de umidade relativa menor que $50 \%$ pode ser danoso aos pintainhos na primeira semana de vida, uma vez que pode levar à desidratação das aves. Portanto, os valores médios registrados pelos sensores, para a umidade do ar, neste experimento, encontram-se dentro da faixa recomendada, a fim de evitar prejuízos para as aves.

Entre o sétimo e o $34^{\circ}$ dia, as temperaturas de globo negro variaram entre $14,9 \pm 0,6^{\circ} \mathrm{C}$ e $32,5 \pm 0,5^{\circ} \mathrm{C}$, com valor médio em torno de $23,1 \pm 0,2^{\circ} \mathrm{C}$, ao passo que a temperatura do ar variou entre valores de $13,9 \pm 0,9^{\circ} \mathrm{C}$ e $32,4 \pm 0,5^{\circ} \mathrm{C}$, média dos registros de todos os sensores, com média para o período de $22,6 \pm 0,4^{\circ} \mathrm{C}$. No mesmo período, a umidade relativa do ar variou entre $39,5 \pm 1,3 \%$ e $98,8 \pm 1,2 \%$, com média de $73,5 \pm 1,5 \%$.

Conforme descrito por Abreu e Abreu (2011), para aves adultas é recomendado que a temperatura ambiental crítica inferior esteja em torno de $15^{\circ} \mathrm{C}$, a zona de conforto térmico permaneça entre 18 e $28^{\circ} \mathrm{C}$ e a temperatura crítica superior não ultrapasse $32^{\circ} \mathrm{C}$. Ao se analisarem os valores médios da temperatura do ar, pode-se concluir que a temperatura ambiental esteve próxima às das condições de conforto para os frangos de corte adultos.

Segundo Medeiros et al. (2005), a faixa ideal para a umidade do ar deve estar entre 50 e $70 \%$. No entanto, para Abreu e Abreu (2011), independentemente da fase de criação, a umidade relativa deve permanecer entre 60 e $70 \%$. Logo, 
de acordo com o registro da umidade do ar, para esse período, em média, os valores encontrados se situam próximos da faixa recomendada para o bom desenvolvimento das aves.

Durante o estresse calórico crônico, do $35^{\circ}$ ao $39^{\circ}$ dia, os valores médios dos termômetros de globo negro, para as temperaturas média, mínima e máxima foram, respectivamente, de $22,9 \pm 0,3^{\circ} \mathrm{C}, 16,5 \pm 0,2^{\circ} \mathrm{C}$ e $32,3 \pm 0,7^{\circ} \mathrm{C}$. Para a temperatura do ar, os valores correspondem a $16,3 \pm 0,2^{\circ} \mathrm{C}, \quad 22,9 \pm 0,3^{\circ} \mathrm{C} \quad$ e $\quad 32,3 \pm 0,7^{\circ} \mathrm{C}$, respectivamente, para as médias dos valores mínimos, médios e máximos. Os valores da umidade relativa alcançados neste período foram: $79,2 \% \pm 2,5 \%$ para a umidade média, $46,3 \% \pm 1,6 \%$ para a média da umidade mínima e $98,1 \% \pm 1,8 \%$ para a média da umidade máxima.

A umidade relativa do ar exerce grande influência no bem-estar e na produtividade dos frangos de corte (Baêta e Souza, 2010). A dissipação do calor corporal, por meio de processos evaporativos, é prejudicada quando as aves são mantidas em ambientes com altas temperaturas do ar associadas com elevada umidade relativa. A capacidade das aves em suportar o calor é inversamente proporcional ao teor de umidade relativa do ar (Ferreira, 2005).

Conforme relatado por Moura (2001), a umidade relativa passa a ser um fator de importância no conforto térmico das aves à medida que a temperatura ambiente ultrapassa $25^{\circ} \mathrm{C}$. Isso porque quanto maior o valor da umidade relativa, menos eficiente é a perda de calor por evaporação.

Em relação à temperatura superficial das aves, não foram detectadas diferenças significativas entre os tratamentos $(\mathrm{P}>0,05)$ (Tab.2). Arjona et al. (1990), em seus estudos, não encontraram diferença nas temperaturas corporal e superficial entre frangos de corte condicionados e não condicionados no período de reexposição e sugeriram que os mecanismos fisiológicos ativados durante o TCP podem ser diferentes dos mecanismos envolvidos no processo de aclimatação, outro tipo de processo de adaptação ao calor, uma vez que o TCP parece não induzir alteração do "set point" fisiológico da ave.

Embora não tenham sido detectadas diferenças entre os tratamentos para a temperatura superficial das aves, Souza e Batista (2012) descreveram a importância da superfície corporal, pois é por meio dela que a energia térmica produzida pelas reações metabólicas é dissipada.

As temperaturas observadas no presente ensaio condizem com aquelas registradas por Nääs et al. (2010) e Schütz (2011), e não indicaram condição de hipertermia.

Tabela 2. Médias da temperatura superficial dos frangos de corte machos no primeiro, terceiro e quinto dias de estresse calórico crônico, segundo os tratamentos

\begin{tabular}{lccc}
\hline \multirow{2}{*}{ Tratamento } & \multicolumn{3}{c}{ Temperatura superficial das aves $\left({ }^{\circ} \mathrm{C}\right)$} \\
\cline { 2 - 4 } & $1^{\circ}$ dia & $2^{\circ}$ dia & $3^{\circ}$ dia \\
\hline Equilíbrio eletrolítico $(\mathrm{E})$ & 40,01 & 39,77 & 39,29 \\
Ausente $\left(\mathrm{E}_{0}\right)$ & 39,99 & 39,90 & 39,10 \\
Presente $\left(\mathrm{E}_{1}\right)$ & & & 39,22 \\
\hline Termocondicionamento $(\mathrm{T})$ & 40,08 & 39,99 & 39,17 \\
\hline Ausente $\left(\mathrm{T}_{0}\right)$ & 39,92 & 39,70 & \\
Presente $\left(\mathrm{T}_{1}\right)$ & & & \\
\hline
\end{tabular}

O TCP exerceu influência significativa $(\mathrm{P}<0,05)$ sobre o ganho de peso e o consumo de ração e interferência altamente significativa $(\mathrm{P}<0,01)$ sobre o índice de conversão alimentar somente no período entre um e sete dias de vida, o que refletiu o aumento da demanda energética em virtude dos mecanismos adaptativos a fim de controlar a homeostase durante as 24 horas de exposição primária ao calor (Sakomura et al., 2005). Portanto, as aves termocondicionadas apresentaram uma pior taxa de conversão alimentar quando comparadas suas médias por meio do teste de Tukey, com o grupo de aves que não sofreu o termocondicionamento (Tab. 3). 
Tabela 3. Médias do ganho de peso (GP), do consumo de ração (CR) e da conversão alimentar (CA), por períodos, para frangos de corte machos, segundo os tratamentos

\begin{tabular}{lcccccccccc}
\hline \multirow{2}{*}{ Tratamento } & \multicolumn{3}{c}{$1^{\circ}$ ao $7^{\circ}$ dia } & \multicolumn{3}{c}{$8^{\circ}$ ao $35^{\circ}$ dia } & \multicolumn{3}{c}{$36^{\circ}$ ao $42^{\circ}$ dia } \\
\cline { 2 - 11 } & $\begin{array}{c}\mathrm{GP} \\
(\mathrm{kg} / \mathrm{ave})\end{array}$ & $\begin{array}{c}\mathrm{CR}^{(1)} \\
(\mathrm{kg})\end{array}$ & $\mathrm{CA}^{(1)}$ & $\begin{array}{c}\mathrm{GP} \\
(\mathrm{kg} / \mathrm{ave})\end{array}$ & $\begin{array}{c}\mathrm{CR}^{(1)} \\
(\mathrm{kg})\end{array}$ & $\mathrm{CA}^{(1)}$ & $\begin{array}{c}\mathrm{GP} \\
(\mathrm{kg} / \mathrm{ave})\end{array}$ & $\begin{array}{c}\mathrm{CR}^{(1)} \\
(\mathrm{kg})\end{array}$ & $\mathrm{CA}^{(1)}$ \\
\hline Equilíbrio eletrolítico (E) & & & & & & & & & & \\
Ausente $\left(\mathrm{E}_{0}\right)$ & $0,11 \mathrm{~b}$ & 0,17 & 1,10 & 2,26 & 3,60 & $1,59 \mathrm{a}$ & 0,75 & 1,47 & 1,96 \\
Presente $\left(\mathrm{E}_{1}\right)$ & $0,12 \mathrm{a}$ & 0,18 & 1,11 & 2,37 & 3,42 & $1,48 \mathrm{~b}$ & 0,71 & 1,48 & 2,16 \\
\hline Termocondicionamento (T) & & & & & & & & & \\
\hline Ausente $\left(\mathrm{T}_{0}\right)$ & $0,12 \mathrm{a}$ & $0,17 \mathrm{~b}$ & $1,04 \mathrm{~b}$ & 2,35 & 3,59 & 1,53 & 0,72 & 1,49 & 2,15 \\
Presente $\left(\mathrm{T}_{1}\right)$ & $0,11 \mathrm{~b}$ & $0,18 \mathrm{a}$ & $1,17 \mathrm{a}$ & 2,29 & 3,44 & 1,54 & 0,74 & 1,45 & 1,97 \\
\hline
\end{tabular}

Médias seguidas por letras distintas nas colunas, dentro de cada tratamento, diferem entre si pelo teste Tukey $(\mathrm{P}<0,05) ;{ }^{(1)}$ : dados ponderados.

O emprego do equilíbrio eletrolítico nas dietas para frangos de corte, por sua vez, exerceu ação significativa $(\mathrm{P}<0,05)$ sobre as variáveis ganho de peso, para os períodos de um a sete dias e de oito a 35 dias, e, para a conversão alimentar, somente no período de oito a 35 dias. As aves que receberam a adição de eletrólitos na dieta apresentaram maior ganho de peso e melhor índice de conversão alimentar quando comparadas às aves que não receberam dieta suplementada, segundo o teste de Tukey a $5 \%$ de probabilidade (Tab. 3). Borges (1997), em seus estudos, também relatou uma melhora no ganho de peso das aves que receberam a adição de eletrólitos na dieta.

O uso dos eletrólitos nas rações mostrou-se favorável $(\mathrm{P}<0,05)$ quando se compararam aves em cuja dieta foram adicionados os eletrólitos com o grupo que não recebeu essa suplementação, pois as aves suplementadas apresentaram maior peso ao $35^{\circ}$ dia (Tab. 4).

Tabela 4. Médias do peso e da taxa de mortalidade, acumuladas, para frangos de corte machos, segundo os tratamentos

\begin{tabular}{|c|c|c|c|c|c|c|}
\hline \multirow[t]{2}{*}{ Tratamento } & \multicolumn{3}{|c|}{$\begin{array}{c}\text { Peso }^{(2)}(\mathrm{kg}) \\
\text { Período (dias) }\end{array}$} & \multicolumn{3}{|c|}{ Mortalidade $(\%)^{(2) ;(3)}$} \\
\hline & 7 & 35 & 42 & 1 a 7 & 1 a 35 & 1 a 42 \\
\hline \multicolumn{7}{|c|}{ Equilíbrio eletrolítico (E) } \\
\hline Ausente $\left(\mathrm{E}_{0}\right)$ & 0,16 & $2,42 b$ & 3,17 & $\begin{array}{c}1,10 \\
(0,21)\end{array}$ & $\begin{array}{c}1,43 \\
(1,04)\end{array}$ & $\begin{array}{c}1,48 \\
(1,19)\end{array}$ \\
\hline Presente $\left(E_{1}\right)$ & 0,16 & $2,54 \mathrm{a}$ & 3,25 & $\begin{array}{c}1,07 \\
(0,14)\end{array}$ & $\begin{array}{c}1,72 \\
(1,96)\end{array}$ & $\begin{array}{c}1,81 \\
(2,28)\end{array}$ \\
\hline \multicolumn{7}{|c|}{ Termocondicionamento $(\mathrm{T})$} \\
\hline Ausente $\left(\mathrm{T}_{0}\right)$ & 0,16 & 2,51 & 3,23 & $\begin{array}{c}1,10 \\
(0,21)\end{array}$ & $\begin{array}{c}1,61 \\
(1,59)\end{array}$ & $\begin{array}{c}1,61 \\
(1,59)\end{array}$ \\
\hline Presente $\left(T_{1}\right)$ & 0,16 & 2,45 & 3,19 & $\begin{array}{c}1,07 \\
(0,14) \\
\end{array}$ & $\begin{array}{c}1,60 \\
(1,56) \\
\end{array}$ & $\begin{array}{c}1,69 \\
(1,86) \\
\end{array}$ \\
\hline
\end{tabular}

Médias seguidas por letras distintas nas colunas, dentro de cada tratamento, diferem entre si pelo teste Tukey $(\mathrm{P}<0,05) ;{ }^{(1)}$ : dados ponderados; ${ }^{(2)}$ : acumulado; ${ }^{(3)}$ : dados transformados em $\sqrt{x+1}$. Valores entre parênteses em percentagem apenas para ilustração.

Em relação à mortalidade das aves, a aplicação do TCP não interferiu nessa variável (Tab. 4), resultado este que divergiu do relatado por Arjona et al. (1990), pois, de acordo com esses autores, aves termocondicionadas ao quinto dia de vida apresentaram menor mortalidade em relação às aves não termocondicionadas, quando foram reexpostas a altas temperaturas durante a sexta semana de vida.

Embora a alteração do balanço eletrolítico seja evitada com a suplementação de eletrólitos na dieta, sua utilização não atuou significativamente sobre a mortalidade das aves que receberam essa suplementação, de acordo com os resultados 
encontrados neste experimento (Tab. 4). Esse achado difere daquele relatado por Teeter et al. (1985), uma vez que, para esses autores, a mortalidade das aves aumenta quando elas são expostas a altas temperaturas em decorrência do desequilíbrio eletrolítico instalado, fruto da ineficiência dos mecanismos compensatórios das aves a fim de garantir a homeostasia.

Pôde-se observar, ao final deste experimento, que o processo de adaptação ao calor, ou seja, o $\mathrm{TCP}$, não exerceu nenhum efeito significativo para as variáveis de desempenho avaliadas. Geraert et al. (1996), Basílio et al. (2001) e Vieira (2008) também discorreram sobre tais observações. Logo, o TCP não promoveu nenhum efeito benéfico sobre as características de desempenho para as aves.

Em relação à taxa de sobrevivência das aves após o TCP, nenhuma interferência estatística significativa $(\mathrm{P}>0,05)$ sobre os parâmetros avaliados foi observada. Contudo, o mesmo resultado não foi encontrado quando se analisou a taxa de sobrevivência após o estresse calórico crônico. O equilíbrio eletrolítico foi prejudicial para as aves que receberam dieta suplementada com os eletrólitos $(\mathrm{P}<0,05)$, (Tab. 5), pois as aves suplementadas apresentaram menores médias da taxa de sobrevivência após o estresse, quando comparadas às aves que não receberam os eletrólitos na ração. Esses resultados contrariam o que era esperado, afinal, os eletrólitos exercem influência no equilíbrio ácido-base, logo, diante da exposição das aves às altas temperaturas, tais componentes adicionados à ração preveniriam a ocorrência do desequilíbrio eletrolítico e, portanto, contribuiriam para a sobrevivência das aves, uma vez que os transtornos metabólicos tão comuns em situações de estresse calórico seriam evitados.

Tabela 5. Médias da taxa de sobrevivência após o termocondicionamento precoce e o estresse calórico crônico para frangos de corte machos, segundo os tratamentos

\begin{tabular}{lcc}
\hline \multirow{2}{*}{ Tratamento } & \multicolumn{2}{c}{ Taxa de sobrevivência (\%) } \\
\cline { 2 - 3 } & Após termocondicionamento ${ }^{(1)}$ & Após estresse calórico crônico $^{(2)}$ \\
\hline Equilíbrio eletrolítico $(\mathrm{E})$ & 99,24 & \\
Ausente $\left(\mathrm{E}_{0}\right)$ & 100,00 & $99,17 \mathrm{a}$ \\
Presente $\left(\mathrm{E}_{1}\right)$ & & $93,98 \mathrm{~b}$ \\
\hline Termocondicionamento $(\mathrm{T})$ & 100,00 & 96,93 \\
\hline Ausente $\left(\mathrm{T}_{0}\right)$ & 99,24 & 96,22 \\
\hline Presente $\left(\mathrm{T}_{1}\right)$ & & \\
\hline
\end{tabular}

Médias seguidas por letras distintas nas colunas, dentro de cada tratamento, diferem entre si pelo teste Tukey $(\mathrm{P}<0,05){ }^{(1)}$ : entre o quarto e o sexto dia de vida; ${ }^{(2)}$ : entre o $34^{\circ}$ e o $40^{\circ}$ dia de vida.

Tanto o emprego do equilíbrio eletrolítico na ração quanto a aplicação do termocondicionamento precoce, no quinto dia de vida, não exerceram influência significativa $(\mathrm{P}>0,05)$ sobre o peso das aves ao abate, o peso da carcaça e o rendimento de carcaça (Tab. 6).

Quando as médias foram comparadas pelo teste Tukey a $5 \%$ de probabilidade, observou-se que não houve diferenças significativas para o peso da gordura cavitária quando foram comparadas as aves cuja ração foi suplementada com eletrólitos com as aves que não passaram por tal suplementação.

O emprego do equilíbrio eletrolítico na ração e a aplicação do termocondicionamento precoce no quinto dia de vida exerceram ação significativa $(\mathrm{P}<0,05)$ sobre os pesos absoluto e relativo do coração (Tab. 7). 
Oliveira et al.

Tabela 6. Médias dos pesos da ave ao abate, da carcaça, da gordura e do rendimento de carcaça para frangos de corte machos, segundo os tratamentos

\begin{tabular}{|c|c|c|c|c|}
\hline \multirow{2}{*}{ Tratamento } & Peso das aves & Carcaça & \multirow{2}{*}{$\begin{array}{c}\text { Gordura } \\
(\mathrm{g})\end{array}$} & \multirow{2}{*}{$\begin{array}{l}\text { Rendimento de } \\
\text { carcaça }(\%)\end{array}$} \\
\hline & \multicolumn{2}{|c|}{$(\mathrm{kg})$} & & \\
\hline Equilíbrio eletrolítico & & & & \\
\hline Ausente $\left(\mathrm{E}_{0}\right)$ & 3,36 & 2,49 & 38,82 & 74,14 \\
\hline Presente $\left(E_{1}\right)$ & 3,25 & 2,49 & 44,48 & 74,70 \\
\hline Termocondicionamentc & & & & \\
\hline Ausente $\left(\mathrm{T}_{0}\right)$ & 3,34 & 2,49 & 42,13 & 74,38 \\
\hline Presente $\left(T_{1}\right)$ & 3,26 & 2,49 & 41,16 & 74,45 \\
\hline
\end{tabular}

Tabela 7. Médias dos pesos absolutos e relativos do coração e do fígado para frangos de corte machos, segundo os tratamentos

\begin{tabular}{lcccc} 
Tratamento & $\begin{array}{c}\text { Peso coração } \\
(\mathrm{g})\end{array}$ & $\begin{array}{c}\text { Relação peso } \\
\text { coração/peso } \\
\text { carcaça (\%) }\end{array}$ & Peso fígado (g) & $\begin{array}{c}\text { Relação peso } \\
\text { fígado/peso } \\
\text { carcaça (\%) }\end{array}$ \\
\hline Equilíbrio eletrolítico $(\mathrm{E})$ & & & & \\
\hline Ausente $\left(\mathrm{E}_{0}\right)$ & $18,10 \mathrm{a}$ & $0,73 \mathrm{a}$ & 57,02 & 2,29 \\
Presente $\left(\mathrm{E}_{1}\right)$ & $16,82 \mathrm{~b}$ & $0,68 \mathrm{~b}$ & 56,37 & 2,27 \\
\hline Termocondicionamento $(\mathrm{T})$ & & & & \\
\hline Ausente $\left(\mathrm{T}_{0}\right)$ & $17,99 \mathrm{a}$ & $0,72 \mathrm{a}$ & 58,03 & 2,33 \\
Presente $\left(\mathrm{T}_{1}\right)$ & $16,93 \mathrm{~b}$ & $0,68 \mathrm{~b}$ & 55,36 & 2,22 \\
\hline
\end{tabular}

Médias seguidas por letras distintas nas colunas, dentro de cada tratamento, diferem entre si pelo teste Tukey $(\mathrm{P}<0,05)$.

As aves termocondicionadas apresentaram menor peso do coração em relação às aves mantidas em ambiente termoneutro, resultado também descrito por Yahav e Hurwitz (1996), os quais relataram que as aves termocondicionadas apresentaram menor massa cardíaca.

Já as aves que não receberam a adição dos eletrólitos na dieta apresentaram as maiores médias para os pesos absoluto e relativo do coração.

Em relação ao peso do fígado absoluto e relativo, nenhum dos parâmetros estudados exerceu influência significativa $(\mathrm{P}>0,05)$ sobre esse órgão (Tab. 7). Todavia, essa observação difere do descrito por El-Moniary et al. (2010), pois, segundo esses autores, houve diferença significativa do peso desse órgão entre os grupos que sofreram o TCP e os que não sofreram.

Plavnik e Yahav (1998) relataram que aves expostas ao calor apresentaram uma redução do peso relativo do fígado e atribuíram esse achado à redução na atividade metabólica. Para Özkan et al. (2006), a diminuição de alguns órgãos, como o fígado, pode ser explicada como uma importante resposta dos frangos ao estresse calórico.

\section{CONCLUSÃO}

As estratégias, termocondicionamento precoce e equilíbrio eletrolítico, utilizadas neste experimento para minimizar os efeitos de um ambiente térmico adverso, mostraram-se ineficazes para amenizar os efeitos do estresse calórico crônico em frangos de corte.

\section{REFERÊNCIAS}

ABREU, V.M.N.; ABREU, P.G. Os desafios da ambiência sobre os sistemas de aves no Brasil. Rev. Bras. Zootec., v.40, p.1-14, 2011.

ARJONA, A.A.; DENBOW, D.M.; WEAVER JR, W.D. Neonatally-induced thermotolerance: physiological responses. Comp. Biochem. Physiol. A Comp. Physiol., v.95, p.393-399, 1990.

BAÊTA, F.C.; SOUZA, C.F. Radiação solar, temperature e umidade do ar. In: BAÊTA, F.C.; SOUZA, C.F. Ambiência em edificações rurais: conforto animal. 2.ed. Viçosa: UFV, 2010. Cap 12, p.129-150. 
BASILIO, V.; VILARIÑO, M.; YAHAV, S.; PICARD, M. Early age thermal conditioning and a dual feeding program for male broilers challenged by heat stress. Poult. Sci., v.80, p.29-36, 2001.

BORGES, S.A. Suplementação de cloreto de potássio e bicarbonato de sódio para frangos de corte durante $o$ verão. 1997. 84f. Dissertação (Mestrado em Zootecnia) -Faculdades de Ciências Agrárias e Veterinárias - UNESP, Campus de Jaboticabal, Jaboticabal, SP.

El-MONIARY, M.M.A.; HEMID, A.A.; ELWARDANY, I. et al. The effect of early age heat conditioning and some feeding programs for heatstressed broiler chicks on: 1 - Productive Performance. World J. Agric. Sci., v.6, p.689-695, 2010 .

FERREIRA, R.A. Ambiência em construções rurais para aves. In: FERREIRA, R.A. Maior produção com melhor ambiente para aves, suínos e bovinos. Viçosa: Aprenda Fácil, 2005. 371p.

GERAERT, P.A.; PADILHA, J.C.F.; GUILLAUMIN, $\mathrm{S}$. Metabolic and endocrine changes induced by chronic heat exposure in broiler chickens: growth performance, body composition and energy retention. Br. J. Nutr., v.75, p.195-204, 1996.

GONZALEZ-ESQUERRA， R.; LEESON, S. Physiological and metabolic responses of broilers to heat stress - implications for protein and amino acid nutrition. World's Poult. Sci. J., v.62, p.282-295, 2006.

MEDEIROS, C.M.; BAÊTA, F.C.; OLIVEIRA, R.F.M. et al. Efeitos da temperature, umidade relative e velocidade do ar em frangos de corte. Eng. Agricult., v.13, p.277-286, 2005

MENEGALI, I.; TINOCO, I.F.F.; CARVALHO, C.C.S. et al. Comportamento de variáveis climáticas em sistemas de ventilação mínima para produção de pintos de corte. Rev. Bras. Eng. Agríc. Amb., v.17, p. 106-113, 2013.

MONGIN P. Recent advances in dietary anion-cation balance: applications in poultry. Proc. Nutr. Soc., v.40, p.285-294, 1981.

MOURA, D.J. Ambiência na avicultura de corte. In: SILVA, I.J.O. Ambiência na produção de aves em clima tropical. Piracicaba: FUNEP, 2001. 185p.

NÄÄS, I.A.; ROMANINI, C.E.B.; NEVES, D.P. et al. Broiler surface temperature distribution of 42 day old chickens. Sci. Agríc., v.67, p.497-502, 2010.
ÖZKAN, S.; PLAVNIK, I.; YAHAV, S. Effects of early feed restriction on performance and ascites development in broiler chickens subsequently raised at low ambient temperature. J. Appl. Poult. Res., v.15, p.9-19, 2006.

PLAVNIK, I.; YAHAV, S. Effect of environmental temperature on broiler chickens subjected to growth restriction at an early age. Poult. Sci., v.77, p.870-872, 1998.

ROSTAGNO, H.S.; ALBINO, L.F.T.; DONZELE, J.L. et al. Tabelas brasileiras para aves e suínos: composição de alimentos e exigências nutricionais. 3.ed. Viçosa, MG: UFV, 2011. 186p.

SAKOMURA, N.K.; LONGO, F.A.; OVIEDORONDÓN, E.O. et al., A. Modeling energy utilization and growth parameter description for broiler chickens. Poult. Sci., v.84, p.1363-1369, 2005.

SALGADO, D.D.; NÄÄS, I.A. Avaliação de risco à produção de frangos de corte do estado de São Paulo em função da temperatura ambiente. Rev. Eng. Agríc., v.30, p.367-376, 2010.

SCHÜTZ, E.S. Variabilidade do ambiente térmico em galpão para frango de corte e sua influência nas respostas fisiológicas e comportamento das aves. 2011. 72f. Dissertação (Mestrado em Ciência Animal) - Universidade Federal de Goiás - UFG, Escola de Veterinária e Zootecnia, Goiânia, GO.

SOUZA, B.B.; BATISTA, N.L. Os efeitos do estresse térmico sobre a fisiologia animal. Agropecu. Cient. Semiárido, v.8, p.6-10, 2012.

TEETER, R.G.; SMITH, M.O.; OWENS, F.N.; ARP, S.C. Chronic heat stress and respiratory alkalosis: occurrence and treatment in broiler chickens. Poult. Sci., v.64, p.1060-1064, 1985.

UBABEF. UNIÃO BRASILEIRA DE AVICULTURA. Relatório anual. 2014. Disponível em:

http://www.ubabef.com.br/publicacoes? $\mathrm{m}=75 \&$ date $=2$ 014-03>. Acessado em: 23 mar. 2015.

VIEIRA, B.S. Influência do condicionamento térmico precoce e do fotoperíodo diário sobre o desempenho e a tolerância térmica de frangos de corte em fase final de criação. 2008. 63f. Dissertação (Mestrado em Zootecnia) - Faculdades de Ciências Agrárias e Veterinárias - UNESP, Campus de Jaboticabal, Jaboticabal.

YAHAV, S.; HURWITZ, S. Induction of thermotolerance in male broiler chickens by temperature conditioning at an early age. Poult. Sci., v.75, p.402-406, 1996. 